\title{
Toxoplasmal and Toxocaral Infections: A Clinical Investigation into Their Relationship
}

\author{
R. A. WISEMAN,* PH.D., M.R.C.S., L.R.C.P., D.T.M.\& H.; D. G. FLECK, $†$ M.D., M.R.C.PATH. \\ A. W. WOODRUFF, $\ddagger$ M.D., PH.D., F.R.C.P. (LOND.,ED.)
}

British Medical fournal, 1970, 4, 152-153

\begin{abstract}
Cummary: An investigation was carried out to determine whether a relationship existed between infections with Toxoplasma gondii and Toxocara canis. Antibodies were sought by the toxoplasma dye test and the toxocara skin sensitivity test. Sixty-seven patients were examined in the United Kingdom; 38 had positive toxoplasma dye tests, two of these being toxocara-positive; and 29 had negative dye tests, six of them being toxocara-positive. From the total of eight toxocarapositive patients antibodies to toxoplasma were detected in two, an incidence no greater than that expected for a normal population.
\end{abstract}

Sera from 60 toxocara-positive African patients were examined; 20 possessed antibodies to Toxoplasma. Analysis according to age group or geographical location indicated that this incidence was no greater than that expected for patients without evidence of toxocaral infection.

This study therefore showed no causal or clinically important relationship between toxoplasmal and toxocaral infections.

\section{Introduction}

Evidence has recently been adduced that Toxoplasma gondii, a coccidian-like protozoon, is probably related to the genus Isospora (Hutchison et al., 1970). The mode of spread of this disease in humans, however, is not yet fully understood. Hutchison (1965) suggested that the nematode ova of domestic animals may be concerned in toxoplasmal transmission, and later he thought it probable that the Toxoplasma organisms travelled within the helminth ovum (Hutchison, 1967). Various experiments (Hutchison, 1965, 1967; Jacobs quoted by Zimmerman, 1966) with Toxocara cati infected cats indicated that this could happen. An important question still remained, however: how relevant was this to the transmission of toxoplasmosis in clinical practice? To elucidate this an investigation was carried out to determine whether a significant proportion of patients with positive toxoplasma dye tests had evidence of past or present toxocaral infection and, alternatively, to investigate whether toxoplasmal antibodies were present in those patients with positive toxocaral skin tests.

\section{Methods}

Toxoplasma Dye Test.-The sera were tested for toxoplasma antibodies with the dye test method of Sabin and Feldman (1948) as modified by Fleck and Payne (1963). All ihe sera were examined at the Public Health Laboratory, St. George's Hospital, Tooting Grove, London, under identical conditions. A positive dye test was taken to be one in which the titre was $1 / 16$ or greater

Toxocara Skin Test.-The method of preparing the

- Research Fellow, Department of Clinical Tropical Medicine, London School of Hygiene and Tropical Medicine. Present Address: Clinica Research Department, Imperial Chemical Industries Limited, Alderley Park, Cheshire.

t Director, Public Health Laboratory, St. George's Hospital, London S.W.17.

\& Director, Medical Unit, Hospital for Tropical Diseases, and Wellcome Professor of Clinical Tropical Medicine, Department of Clinical Tropical Medicine, London School of Hygiene and Tropical Medicine, London W.C.1. intradermal skin testing antigen followed that of previous reports (Woodruff and Thacker, 1964; Wiseman and Woodruff, 1970).

\section{Results}

A total of 127 patients were investigated -67 in the United Kingdom and 60 in Africa. Of the 67 seen in the United Kingdom eight reacted positively to the toxocara skin test. Toxoplasma antibodies were found in the sera of 38 patients, of whom two were positive toxocara reactors; toxoplasma antibodies were absent in 29 , of whom six were positive toxocara reactors. Only two patients were positive to both tests. The ages of these patients, together with the results of the tests for each age group, are shown in Table I.

Sera from the 60 African patients were tested. All the sera were from patients who were positive to the toxocara skin test. Of the 34 sera from Uganda six were positive to the toxoplasma dye test; of seven from Masailand, in Kenya, five were positive; of 13 from Dar-es-Salaam, Tanzania, four were positive; and of six from Yoruba, in Western Nigeria, five were positive. The results of the dye tests in the toxocarapositive African patients are analysed according to age group in Table II. The incidence of positive dye tests according to the geographical location is given in Table III, which shows that the prevalence varied considerably-from $18 \%$ in Uganda to about $84 \%$ in Nigeria, with an average for all regions of $33 \%$.

\section{Discussion}

After infection with Toxoplasma gondii the toxoplasma dye test remains positive for many years even when the infection is no longer active (Fleck, 1969). Similarly, the toxocara skin sensitivity test has been shown to be a reliable and specific indicator of both past and present toxocaral infections (Wiseman and Woodruff, 1967, 1970). These investigations

Table I.-Prevalence of Positive Toxoplasma and Toxocara Antibody Tests in Patients in the United Kingdom According to Age

\begin{tabular}{|c|c|c|c|c|c|}
\hline \multirow{2}{*}{\multicolumn{2}{|c|}{ Age }} & \multirow{2}{*}{$\begin{array}{l}\text { No. of } \\
\text { Patients }\end{array}$} & \multicolumn{3}{|c|}{ No. Positive with } \\
\hline & & & $\begin{array}{c}\text { Toxoplasma } \\
\text { Dye Test }\end{array}$ & $\begin{array}{l}\text { Toxocara } \\
\text { Skin Test }\end{array}$ & Both Tests \\
\hline $\begin{aligned} & 0-10 \ldots \\
& 11-20 \cdots \\
& 21-30 \cdots \\
& 31+ . \\
& \text { Not recorded }\end{aligned}$ & $\begin{array}{ll}. & \ldots \\
\cdots & \cdots \\
\cdots & \cdots \\
. & \cdots\end{array}$ & $\begin{array}{r}7 \\
11 \\
25 \\
19 \\
5\end{array}$ & $\begin{array}{r}2 \\
5 \\
17 \\
11 \\
3\end{array}$ & $\begin{array}{l}3 \\
2 \\
2 \\
1 \\
0\end{array}$ & $\begin{array}{l}\mathbf{1} \\
\mathbf{1} \\
\mathbf{0} \\
\mathbf{0} \\
\mathbf{0}\end{array}$ \\
\hline Total & . & 67 & 38 & 8 & 2 \\
\hline
\end{tabular}

TABle II.-Prevalence of Positive Toxoplasma Dye Tests in African ToxocaraPositive Patients According to Age

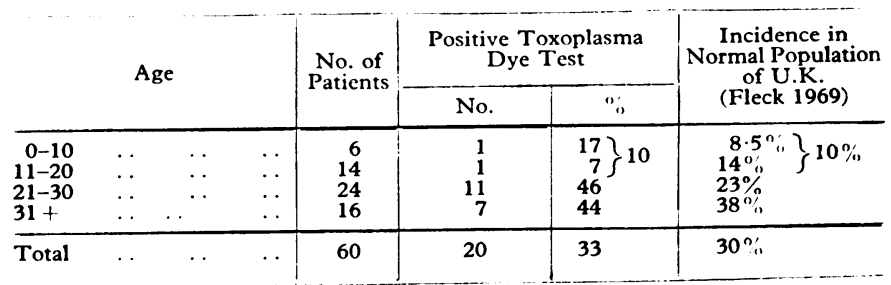



TABle III.-Prevalence of Positive Toxoplasma Dye Tests in African
Toxocara-Positive Patients According to Location

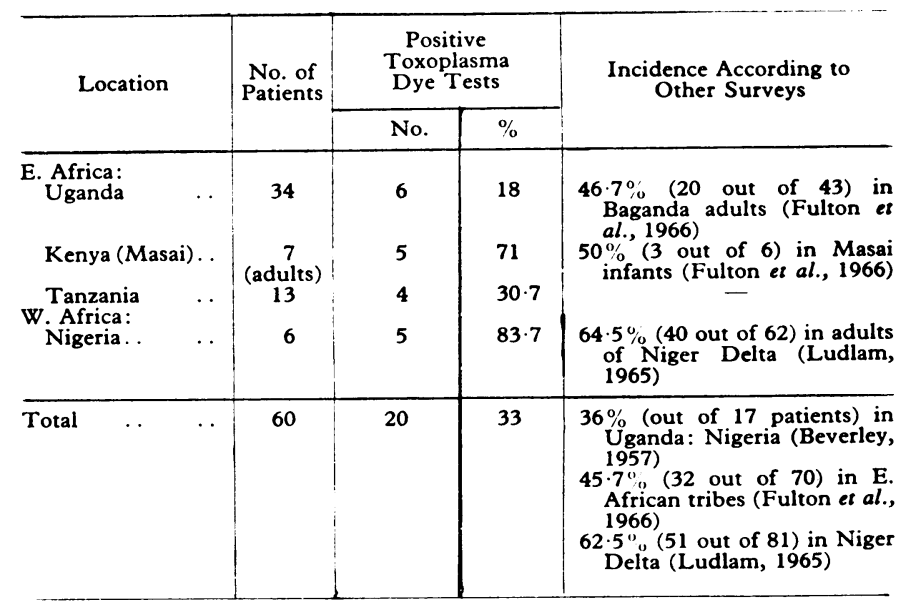

are therefore valuable epidemiological tests when attempts are made to assess whether any relationship exists between two diseases, since either infection or both may have been acquired many years previously.

Though the relationship suspected by Hutchison (1965) was between Toxoplasma gondii and Toxocara cati, the present investigation was performed with a suspension of Toxocara canis, it being believed that the toxocara skin test is not so specific as to exclude patients infected with Toxocara cati. Of the 67 patients investigated in the United Kingdom 38 had positive toxoplasma dye tests and $8(12 \%)$ were positive reactors to the toxocara skin test. This latter figure is in close agreement with the $12.7 \%$ of positive toxocara reactors found by Wiseman and Woodruff (1968) in patients selected for investigation by similar criteria. Of the 38 patients with antibodies to toxoplasma, two were positive to the toxocara skin test; but of the 29 patients without toxoplasmal antibodies six were toxocara-positive. Since these numbers of patients are small no definite conclusions can be drawn, but it appears that a significant association between the two conditions is unlikely.

The incidence of positive dye tests in the normal population varies according to age-in the United Kingdom increasing steadily from $8.5 \%$ at $0-10$ years to $41 \%$ at $51-60$ years (Fleck, 1969). The eight toxocara-positive patients were aged from 8 to 54 years; it was therefore statistically probable that one or two would have positive toxoplasma dye tests, and the fact that only two did so suggests that there is no clinically important relationship between the two infections.
The sera of the African patients were selected for this investigation as all of them had reacted positively to the toxocara antigen; sera from non-reactors to the toxocara antigen from the same localities were unfortunately not available in sufficient numbers for any comparison to be worth while. There was, however, no significant difference between the incidence of positive toxoplasma dye tests in the toxocarapositive African patients at any age group as compared with the incidence in a normal population in the United Kingdom (Table II). Furthermore, the incidence of positive dye tests found in each country does not apparently differ from the expected incidence in that geographical area (see Table III). In making this comparison account must be taken of the fact that in some surveys carried out by other observers-for . example, Fulton et al. (1966) with Masai infants-patients of a lower age group than in this survey were examined, and therefore the incidence of toxoplasmosis found in them was lower than in the present survey. The number of positive toxoplasma dye tests in these toxocara-positive patients is therefore no greater than that which might have been expected to occur in similar numbers of patients chosen at random; therefore from this study no causal relationship between infections with Toxoplasma gondii and nematodes of Toxocara species can be adduced.

Most of the patients examined in the United Kingdom were seen in the Uveitis Clinic of the Institute of Ophthalmology, London, by kind permission of Professor E. S. Perkins. Thanks are also due to Mr. E. Uthuba-Hattari for performing the toxoplasma dye tests.

\section{REFERENCES}

Beverley, J. K. A. (1957). Transactions of the Royal Society of Tropical Medicine and Hygiene, 51, 118.

Fleck, D. G. (1969). Public Health (London), 83, 131

Fleck, D. G., and Payne, R. A. (1963). Monthly Bulletin of the Ministry of Health and the Public Health Laboratory Service, 22, 97.

Fulton, J. D., Fleck, D. G., and Payne, R. A. (1966). Fournal of Hygiene, 64, 75.

Hutchison, W. M. (1965). Nature, 206, 961.

Hutchison, W. M. (1967). Transactions of the Royal Society of Tropical Medicine and Hygiene, 61, 80.

Hutchison, W. M., Dunachie, J. F., Siim, J. Chr., and Work, K. (1970). British Medical fournal, 1, 142.

Ludlam, G. B. (1965). Transactions of the Royal Society of Tropical Medicine

and Hygiene, 59, 83.

Wiseman, R. A., and Woodruff, A. W. (1967). Transactions of the Royal Society of Tropical Medicine and Hygiene, 61, 827.

Wiseman, R. A., and Woodruff, A. W. (1968). British Medical fournal, 1 , 677. Wiseman, R. A., and Woodruff, A. W. (1970). Transactions of the Royal
Society of Tropical Medicine and Hygiene, ${ }^{64}{ }^{239}$.

Woodruff, A. W., and Thacker, C. K. (1964). British Medical Fournal, 1 1001 .

Zimmerman, L. E. (1966). Archives of Ophthalmology, 76, 159. 